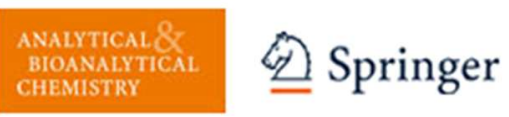

\title{
Desorption electrospray ionization-high resolution mass spectrometry for the screening of veterinary drugs in cross contaminated feedstuffs
}

\begin{tabular}{|r|l|}
\hline Journal: & Analytical and Bioanalytical Chemistry \\
\hline Manuscript ID: & ABC-00901-2015.R1 \\
\hline Type of Paper: & Research Paper \\
\hline Date Submitted by the Author: & n/a \\
\hline Complete List of Authors: & $\begin{array}{l}\text { Seró, Raquel; University of Barcelona, Analytical Chemistry } \\
\text { Nuñez, Oscar; University of Barcelona, Analytical Chemistry } \\
\text { Bosch, Jaume; Laboratori Agroalimentari de Catalunya, } \\
\text { Grases, José; Laboratori Agroalimentari de Catalunya, } \\
\text { Rodríguez, Pilar; Laboratori Agroalimentari de Catalunya, } \\
\text { Moyano, Encarnacion; University of Barcelona, Analytical Chemistry; } \\
\text { Galceran Huguet, Martia Teresa; University of Barcelona, Analytical } \\
\text { Chemistry }\end{array}$ \\
\hline Keywords: & $\begin{array}{l}\text { desorption electrospray ionization, high resolution mass spectrometry, } \\
\text { veterinary drugs, cross-contamination, ambient mass spectrometry }\end{array}$ \\
\hline
\end{tabular}


DESORPTION ELECTROSPRAY IONIZATION-HIGH RESOLUTION MASS

4 SPECTROMETRY FOR THE SCREENING OF VETERINARY DRUGS IN 5 CROSS-CONTAMINATED FEEDSTUFFS

6 R. Seró ${ }^{1}$, O. Núñez ${ }^{1,3}$, J. Bosch ${ }^{2}$, J.M. Grases ${ }^{2}$, P. Rodríguez ${ }^{2}$, E. Moyano ${ }^{*}$, M. T. 7 Galceran $^{1}$

8

$9{ }^{1}$ Department of Analytical Chemistry, University of Barcelona. Diagonal 645, 08028, 10 Barcelona, Spain.

$11{ }^{2}$ Laboratori Agroalimentari, Generalitat de Catalunya, Vilassar de Mar s/n, 08348,

12 Cabrils, Spain.

$13{ }^{3}$ Serra Hunter Fellow, Generalitat de Catalunya (Spain)

14

* Corresponding author: E. Moyano

Department of Analytical Chemistry, University of Barcelona. Diagonal 645, 08028,

Barcelona, Spain.

Phone: +34-93-403-9277

Fax: +34-93-402-1233

e-mail: encarna.moyano@ub.edu

21

Keywords: veterinary drugs, ambient mass spectrometry, desorption electrospray ionization, high resolution mass spectrometry, cross-contamination 
In this study, a desorption electrospray ionization-high resolution mass spectrometry (DESI-HRMS) screening method was developed for fast identification of veterinary drugs in cross-contaminated feedstuffs. The reliable detection was performed working at high resolution (70,000 full with half maximum, FWHM) using an orbitrap mass analyser. Among the optimized DESI parameters, the solvent (acetonitrile-water, $80: 20, v / v)$ and the sample substrate (poly-tetrafluoroethylene, PTFE) were critical to obtain the best sensitivity. To analyse the solid feed samples, different approaches were tested and a simple solid-liquid extraction and the direct analysis of an aliquot $(2 \mu \mathrm{L})$ of the extract after let it dry on the PTFE printed spot provided the best results. The identification of the veterinary drugs (target and non-target) in the cross-contaminated feedstuffs based on the accurate mass measurement and the isotopic pattern fit was performed automatically using a custom-made database. The positive crosscontaminated feed samples were quantified by ultra-high performance liquid chromatography-tandem mass spectrometry (UHPLC-MS/MS). The results obtained demonstrate that DESI-HRMS can be proposed as a fast and suitable screening method to identify positive cross-contaminated feedstuffs reducing the number of samples to be subsequently quantified by UHPLC-MS/MS thus improving the productivity in quality control laboratories. 


\section{Introduction}

One of the most effective ways for farmers to administer medicines to the livestock after veterinary prescription is by medicated feed. The production and marketing of medicated feed are regulated by the European Commission [1] and many European countries have implemented residue monitoring plans to control the illegal use of these substances in feed and the misuse of authorised veterinary medicines, and to minimise drug residual occurrence [2]. The European Parliament and the Council of the European Union have established, under the Regulation 183/2005/EC, the general rules to control feed production and their manufacturing conditions, thus ensuring the traceability of feed [3]. Despite the requirements set for feed business, multi-product plants manufacture both medicated and non-medicated feed in the same production line $[4,5]$ and, under practical conditions, during the production a certain percentage of the previous batch remains in the production circuit contaminating the subsequent feed batch. This "carry-over" or "cross-contamination" is recognized by the Current Good Manufacturing Practice Regulations (CGMPR) which requires adequate clean-out procedures to prevent the "unsafe" contamination. This cross-contamination may result in the exposure of non-target animals and, as a consequence, potential health risks for these animals as well as the presence of residue contamination in food products might occur. Several studies have shown that production of premixes and composed feed free of contamination is, in practice, very difficult in the existing multi-product plants [5]. If the drug carry-over results in the unsafe contamination of other medicated or nonmedicated feed, it constitutes a violation of the maximum limits established by Directive 574/2011/EC [6], resulting in adulterated feed.

To increase the productivity in agricultural and food laboratories the rapid screening of (il)legal preparations to identify veterinary drugs in feedstuffs is widely demanded [7-13]. Today, liquid chromatography coupled to tandem mass spectrometry (LC-MS/MS) is the technique most currently used for the determination of drug contamination in feed samples. However, the complexity of feed samples requires extensive and time-consuming sample treatment protocols to provide clean extracts to be analyzed by the selective target LC-MS/MS methods [9, 10, 12-16]. In the last decade, the introduction of high resolution mass spectrometry (HRMS) has improved selectivity and specificity of LC-MS methods. However, only few methods have been published until now regarding the analysis of feed samples by LC-HRMS [17-19].

The recent introduction of ambient ionization techniques in mass spectrometry such as desorption electrospray ionization (DESI) [20] and direct analysis in real time 
(DART) [21] open the possibility for the direct analysis of compounds from the sample acquiring the mass spectra from bulk samples in their native state and without sample treatment or chromatographic separation $[22,23]$. The analysis is performed in few seconds, which is a significant advantage when compared to conventional analytical methods. Particularly, in DESI a spray of charged liquid droplets is directed to the sample creating a solvent film on the surface. Further droplets hit this film splashing secondary droplets containing the analytes into the mass spectrometer [25]. Since their introduction, ambient techniques have been applied to multitude of fields, such as environmental [24-26], food [27-29], clinical diagnosis [30] and forensic analysis [31]. Nevertheless, only few papers described the use of ambient techniques for the analysis of veterinary drugs [33, 34]. DESI-MS has been applied for a rapid screening of hormones and veterinary drugs in samples from forensic investigations using an ion trap (IT) mass analyzer, although authors indicated the difficulty to detect tetracyclines under the DESI-MS conditions used [32]. Moreover, DART-HRMS has been applied for the target analysis of coccidiostats in feed samples using an orbitrap mass analyser demonstrating the feasibility of this ambient technique to quantify these analytes at the levels established by the EU legislation [33].

The aim of this work is to study the applicability of DESI coupled to HRMS (orbitrap) for the fast screening of veterinary drugs in cross contaminated feed samples in order to improve throughput analysis and productivity of feed control laboratories. For this purpose, the most critical DESI-HRMS working parameters are evaluated and discussed. A home custom made database with mass spectral information of veterinary drugs is used for the fast identification of target compounds and suspect crosscontaminants.

\section{Experimental}

\subsection{Chemicals and materials}

Nine veterinary drugs were used as model standards for the optimization of DESI parameters. Diclazuril (DIC), narasin (NAR), monensin (MON) oxibendazole (OXI), amoxicillin (AMO), lincomycin (LIN), tiamulin (TIA) and spiramycin (SPI) were purchased from Sigma-Aldrich (Steinheim, Germany) while tylosin (TYL) was purchased from Rikilt (Wageningen, Netherlands). All the standards were of the highest purity available. LC-MS grade methanol $(\mathrm{MeOH})$, acetonitrile $(\mathrm{ACN})$ and water were supplied by Sigma-Aldrich (Steinheim, Germany) as well as formic acid ( $\geq 99 \%)$. 
Nitrogen (99.9995\% purity) used for nebulization gas was supplied by Linde Group (Barcelona, Spain). Individual stock solutions $\left(1 \mathrm{mg} \mathrm{mL}^{-1}\right)$ were prepared in $\mathrm{MeOH}$ and stored at $4^{\circ} \mathrm{C}$, while the working standard mixtures were prepared weekly by appropriate dilution in $\mathrm{ACN}$.

\subsection{Desorption Electrospray Ionization-High Resolution Mass Spectrometry}

A desorption electrospray ionization (DESI) source (Omnispray Ion Source, Prosolia Inc., Indianapolis, IN) equipped with an 1D moving stage and coupled to a quadrupole-orbitrap mass spectrometer (Q-Exactive, Thermo Fisher Scientific, San José, CA, USA) was used in this study. DESI solvent (acetonitrile:water, 80:20 v:v) was infused by a syringe pump at $2.5 \mu \mathrm{L} \min ^{-1}$ and $\mathrm{N}_{2}$ gas was used as nebulizer gas at a pressure of 9 bar. DESI solvent was directed onto the sample surface at a nebulization capillary angle of $55^{\circ}$ and a distance of $\sim 9.2 \mathrm{~mm}$ between the mass spectrometer inlet and the spray tip. The electrospray voltage was $\pm 4.8 \mathrm{kV}$ (positive/negative). The transfer capillary temperature was set at $250^{\circ} \mathrm{C}$. Samples were deposited onto microscope glass slides of $7.1 \mathrm{~mm}^{2}$ polytetrafluoroethylene (PTFE) (Teflon, McMasterCarr, Santa Fe, CA, USA) printed spots. The Q-Exactive mass spectrometer was operated in positive and negative ion mode within an $\mathrm{m} / \mathrm{z}$ scan range of 100-1,000 $\mathrm{m} / \mathrm{z}$. Omni Spray ion source software v2.0 (Omnispray Ion Source, Prosolia Inc., Indianapolis, IN) was used to control the DESI source, while data acquisition and data processing were performed with Xcalibur software $v 2.2$ and Exact Finder software $v 2.0$ (Thermo Fisher Scientific, San José, CA, USA), respectively.

To control the reproducibility and to determine the initial DESI conditions, a red permanent marker (containing rhodamine-6G dye) purchased from Fine Sharpie (Stanford Corp., Oak Brook, IL) was used. Accurate mass calibration was performed in the Q-Exactive mass spectrometer every $48 \mathrm{~h}$ in both positive and negative ion modes. For positive ion mode a calibration solution consisting of caffeine, MRFA peptide, Ultramark 1621 and n-butylamine in acetonitrile/methanol/water containing 1\% formic was used, while for negative ion mode calibration a mixture solution containing dodecyl sulface, sodium taurocholate and Ultramark 1621 in acetonitrile/methanol/water with $1 \%$ of formic acid was used.

\subsection{Samples and sample preparation}



Laboratori Agroalimentari of the Generalitat de Catalunya (LAC) for their analysis by UHPLC-MS/MS [10] were used to demonstrate the applicability of the DESI-HRMS in this study.

Feed samples were extracted using a simple and fast solid-liquid extraction procedure. Briefly, $2 \mathrm{~g}$ of the sample were placed in a $15-\mathrm{mL}$ polypropylene centrifuge tube and were extracted for $15 \mathrm{~min}$ in an ultrasonic bath (Bransonic B-5510, Soest, Germany) using $5 \mathrm{~mL}$ of a mixture of acetonitrile/water $(80: 20, v / v)$ acidified with $1 \%$ formic acid. Finally, the extract was centrifuged (Selecta-Macrotronic, J.P. SELECTA S.A, Abrera, Spain) for $1 \mathrm{~min}$ at 3,500 rpm and $2 \mu \mathrm{L}$ of the supernatant were deposited onto the PTFE printed spot and let it dry for $5 \mathrm{~min}$ at ambient temperature before the DESI-HRMS analysis.

\section{Results and discussion}

\subsection{DESI-HRMS}

Nine veterinary drugs (macrolides, coccidiostats, and benzimidazoles) were used as model compounds to evaluate and to set up the DESI-HRMS working conditions. Standard solutions in pure acetonitrile $\left(10 \mu \mathrm{g} \mathrm{mL}^{-1}\right)$ were deposited on PTFE surfaces and DESI full mass spectra were recorded using both positive and negative ion modes. Fig. 1 shows the mass spectra obtained for a standard mixture where MON, NAR, TIA, TYL, ESP, LIN and OXI were detected in positive ion mode mainly as protonated molecules $[\mathrm{M}+\mathrm{H}]^{+}$, except MON and NAR for which sodium adducts $[\mathrm{M}+\mathrm{Na}]^{+}$were observed. Regarding DIC and AMOX, they were only detected in negative ion mode as deprotonated molecules $[\mathrm{M}-\mathrm{H}]^{-}$. Additionally, the DESI-HRMS analysis of individual standard solutions indicated that no significant in-source CID fragmentation and other adducts formation were expected for these compounds, allowing us to assign one ion (isotope cluster) to each veterinary drug during the screening.

The DESI-HRMS screening of veterinary drugs in feed samples was based on the accurate mass measurement and the isotope pattern distribution of the detected ions. Orbitrap can operate at a mass resolution high enough to prevent possible endogenous matrix interferences without sacrificing sensitivity. However, a compromise between acquisition duty cycle and mass resolution was necessary to provide both accurate mass measurements with mass errors below $5 \mathrm{ppm}$ and enough sensitivity to detect the analytes in the complex mass spectrum. To select the working mass resolution, a blank 
sample extract spiked with the nine veterinary drugs $\left(10 \mu \mathrm{g} \mathrm{mL}^{-1}\right)$ was analyzed at values between 17,500 and 140,000 FWHM (full width half maximum). All target compounds showed a drop in sensitivity when working above 70,000 without any significant improvement in mass accuracy. Thus, this mass resolution was used for further screening analysis.

Moreover, the sensitivity of the DESI-HRMS method also depended on the number of ions accumulated inside the orbitrap and also on the accumulation time applied. Since the automatic gain control (AGC) algorithm controls the number of ions inside the orbitrap to prevent space charge effects, the injection time (accumulation time) had to be optimized. Thus, the AGC was kept constant at $1 \times 10^{6}$ and the injection time was varied between 50 and $500 \mathrm{~ms}$. The best signal was obtained for $300 \mathrm{~ms}$ as injection time. This relatively high injection time compared to conventional ESI is due to the low ion intensity generated in the DESI process that required longer injection times to accumulate a number of ions high enough to obtain a reasonable spectrum.

\subsection{Optimization of DESI working conditions}

To maximize the DESI signal, two main groups of working conditions must be optimized. The first group comprises those conditions related to the electrospray process such as nebulizing gas pressure, electrospray solvent composition, electrospray solvent flow rate and the substrate/surface. The second group is related to the geometrical DESI parameters that include the nebulization capillary angle, the tip distance to the sample surface and the distance to the mass spectrometer inlet. Initial DESI conditions were established using rhodamine-containing marker and the most critical DESI ion source parameters (nebulization capillary angle, tip distance to the sample surface, distance to mass spectrometer inlet, nebulizing capillary gas, solvent flow rate and capillary voltage) were individually optimized using blank feed extracts spiked with a set of veterinary drugs $\left(10 \mu \mathrm{g} \mathrm{g}^{-1}\right)$.

It has been demonstrated that the sample surface (substrate) plays a crucial role in DESI performance. Since the DESI process involves the landing and release of charged particles on a surface, the fundamental features of the solid surface, including its chemical composition and texture, severely affect the energy and charge transfer processes and consequently the ionization efficiency in DESI. Thus, several important parameters such as limit of detection, signal stability, carryover and reproducibility of the DESI method can be influenced by the surface [34]. In this work, three different surfaces were tested as substrates to analyze spiked acetonitrile feed extracts: glass, 
filter paper and PTFE. The highest and most stable signal was observed when using the PTFE surface. In filter paper worse reproducibility than in PTFE was obtained, which can be due to uneven distribution of the analytes on the surface caused by chromatographic effects that occur in the course of the solution deposition [35].

DESI solvent composition and analyte solubility in the DESI solvent have an important effect in both desorption and transfer of analytes from the surface to the mass spectrometer. DESI solvent composition strongly affects electrospray droplets formation influencing the primary droplets size and the droplets charge, as well as the focus of the spray. Additionally, DESI solvent composition could favor the extraction and electrospray ionization of the analyte. To select the most adequate DESI solvent, different solvent mixtures of methanol:water and acetonitrile:water and the addition of formic acid to promote the protonation of target compounds in positive ion mode were evaluated. As an example, the effect of the DESI solvent composition on the ion signal intensity of MON, NAR and TIA in positive ion mode and DIC in negative ion mode is depicted in Fig. 2a. As can be seen, the composition of the DESI solvent dramatically affects the compounds signal. The highest signal intensity, in both positive and negative ion modes, was achieved when using acetonitrile:water. The increase in the compound response may be due to the higher solubility of the analytes in the acetonitrile:water solvent that improves the transfer efficiency of the analytes into the secondary ESI droplets. It should be noted that an important decrease on the relative abundance of the ions generated from the veterinary drugs was observed when adding formic acid to the DESI solvent (Fig. 2a). These results were expected for veterinary drugs such as MON and NAR because the ion abundance of $[\mathrm{M}+\mathrm{Na}]^{+}$, the base peak in the non-acidic DESI solvent, can decrease due to the competition with $[\mathrm{M}+\mathrm{H}]^{+}$ion generated in acidic medium. For acidic compounds that ionized in negative ion mode generating deprotonate molecules $[\mathrm{M}-\mathrm{H}]^{-}$, the ion signal also decreased when using acid in the DESI solvent because the neutral species are favored in the liquid phase. However, unexpected results were observed for basic compounds such as TIA, for which the acidic media should facilitate the protonation of analytes in positive-ion mode. This might be due to an increase in the DESI droplet size caused by the enhancement of the surface tension produced by the higher ionic strength of the acidic DESI solvent (formic acid), in agreement with the results obtained by Green et al. [36]. Moreover, the effect of the organic solvent percentage of the DESI solvent on the ion signal intensity was also studied. The ion abundances observed for each compound using different acetonitrile:water mixtures are shown in Fig. 2b. All compounds studied showed a 
similar behavior. The ion signal intensity increased when increasing the organic solvent content from $50 \%$ to $80 \%$. This could be explained by the highest solubility of the analytes in the enriched acetonitrile solvent mixture. Nevertheless, the ion signal intensity dropped when using $90-100 \%$ acetonitrile probably due to a worse wettability of the surface when using a solvent with lower hydrophilicity (>90\% acetonitrile). The optimal conditions, acetonitrile:water 80/20 (v/v), were supposed to be satisfactory for the other veterinary drugs with similar physicochemical properties to the chemicals studied.

The DESI solvent flow rate and nebulizing gas pressure affect the wetting and the flow dynamics on the surface as well as the size and velocity of the electrospray droplets, thus playing an important role in both ionization and desorption of analytes from the surface [37]. In this study, these parameters were optimized using the previously selected DESI solvent (acetonitrile:water 80/20, v/v). The gas pressure was tested within the range of 7-10 bars and it was observed that when working at gas pressure values below 9 bars the intensity dropped. This might be due to the formation of electrospray droplets of slow velocity and to the generation of secondary droplets with less kinetic energy to escape from the surface. In contrast, when applying a gas pressure of 10 bars the signal also dropped probably because the high gas flow rate pushed the secondary droplets back to the surface leading to enhance droplet splashing. Regarding DESI solvent flow rate, it was varied from 1 to $5 \mu \mathrm{L} \mathrm{min}{ }^{-1}$ and it was observed that when increasing flow rate the signal improved probably due to the better surface wetting. Nevertheless, a wider surface area was eroded thus worsening the spatial resolution [38]. As a compromise between sensitivity and spatial resolution a gas pressure of 9 bars and a DESI solvent flow rate of $2.5 \mu \mathrm{L} \mathrm{min}^{-1}$ were choose as optimal working conditions.

To optimize the geometrical parameters we used acetonitrile:water $(80 / 20, v / v)$ as DESI solvent. The position of the spray tip (both within the spray head and relative to the surface area) is critical for a successful DESI signal. Thus, the nebulizing capillary angle $(\alpha)$ and the tip distance to the sample surface $\left(d_{1}\right)$ have direct effects on the ionization process, while the distance to the mass spectrometer inlet $\left(\mathrm{d}_{2}\right)$ have important effects on the ion collection efficiency and, hence, on the sensitivity of the method. The effect of $\alpha$ on the DESI signal was evaluated by modifying the incident angle $\left(45^{\circ}-75^{\circ}\right)$ of the electrospray tip relative to the surface that changes the impact angle of the droplets on the surface. The highest intensity was observed for an $\alpha$ value of $55^{\circ}$, which is generally used as optimum value in other DESI applications [39]. The $d_{1}$ and $d_{2}$ 
values were varied from 1.5 to $4 \mathrm{~mm}$ and from 4 to $10 \mathrm{~mm}$, respectively. For a DESI solvent flow rate of $2.5 \mu \mathrm{L} \mathrm{min}{ }^{-1}$ the closer was the sprayer to the surface $\left(\mathrm{d}_{1}\right)$, the highest was the signal, being $1.7 \mathrm{~mm}$ the optimal value for all the analytes. Moreover, for $\mathrm{d}_{2}$ the best response was observed at $5 \mathrm{~mm}$ when analyzing the spiked feed extract.

\subsection{DESI-HRMS analytical performance.}

The complexity of the matrix and the wide polarity range among the different chemical groups of the veterinary drugs make the analysis of feedstuffs a challenge. Different sample manipulation strategies were evaluated to screen veterinary drugs in feed. Because of the powder nature of the feed samples studied, the direct analysis by DESI-HRMS was not possible. As a first attempt, we prepared pressed feed pellets of $1.5 \mathrm{~cm}$ in diameter using a manual hydraulic press to get a smooth surface to be screened by DESI-HRMS. However, the dusty texture of the feed samples made difficult to obtain good results because of the damaging of the feed pellet surface by the nebulizing gas and the contamination of the mass spectrometer transfer line by the powdery sample. To enhance the pellets compactness different pressures (from 10 to 15 tons) were tested as well as the addition of boric acid to increase pellet agglutination, although no significant differences were observed.

As an alternative to the direct analysis of the sample surface, a simple solidliquid extraction procedure was considered. Several sample extraction multi-analyte methods based on organic solvent mixtures have been developed for the detection of a wide range of veterinary drugs in animal feed by LC/MS [12, 13, 17, 40] manly using acetonitrile and methanol. Hence, the behaviour of both solvents for the analysis by DESI of feed samples was tested. For this purpose, blank feed extracts extracted individually with these solvents and spiked with the nine representative veterinary drugs $\left(10 \mu \mathrm{g} \mathrm{g}^{-1}\right)$ were deposited onto a PTFE surface after let it dry and were analysed by DESI-HRMS. The results showed that higher ion intensities were obtained when using acetonitrile as extraction solvent since methanol may extract too many matrix compounds that can cause ion suppression. In contrast, acetonitrile allows protein precipitation and enzyme denaturation resulting in cleaner extracts. However, it has been described that the use of only organic solvents (acetonitrile, methanol or combination of both) at different percentages, led to low intensities for non-ionophore coccidiostats (clopidol, ethopabate, amprolium), macrolides and tetracyclines [41]. Moreover, some authors recommend the addition of a small amount of water, up to $20 \%$, to the organic solvent to favour the extraction of polar compounds [40]. So, 
acetonitrile/water $(80 / 20, v / v)$ with $1 \%$ of formic acid recommended to increase the extraction of basic compounds was chosen as extraction solvent for the DESI-HRMS multi-residue method.

The effect of the feed matrix in the ionization efficiency was tested for the nine representative veterinary drugs. A blank feed extract was spiked at $10 \mu \mathrm{g} \mathrm{g}^{-1}$ level and then extracted with acetonitrile:water $(80 / 20, v / v)$ with $1 \%$ formic acid. The mass spectra of this spiked blank feed extract and that obtained for a standard mixture at the same concentration level prepared in acetonitrile:water $(80 / 20, v / v)$ with $1 \%$ formic acid were compared. For all the studied compounds, the ion signal in the spiked feed blank extracts were one order of magnitude lower than in the standard mixture indicating that ion suppression occurs. Even though, limits of detection (LODs) estimated for the tested compounds were lower than $1 \mu \mathrm{g} \mathrm{g}^{-1}$ (Table 1), except for amoxicillin, for which a higher estimated LOD value $\left(15 \mu \mathrm{g} \mathrm{g}^{-1}\right)$ was obtained, probably because of a partial degradation in acidic solutions, especially at low concentration levels [2]. LODs, based on a signal-to-noise ratio of 3:1, were estimated by analyzing blank feed samples spiked with standards at low concentrations. For those compounds that the standard was not available, LODs from sample were calculated taking into account a signal-to-noise ratio of 3:1 and the concentration levels of veterinary drugs quantified by HPLC-MS/MS. These values are below the legal limits legislated for most of the veterinary drugs due to the unavoidable carry-over in the line production $\left(\mu \mathrm{g} \mathrm{g}^{-1}\right.$ levels) except for diclazuril, which the maximum residue level is legislated at $0.01 \mu \mathrm{g} \mathrm{g}^{-1}$ [6].

\subsection{DESI-HRMS screening of feed samples}

To evaluate the applicability of the developed DESI-HRMS method, 50 feed samples (medicated and no medicated feed) received from LAC were analysed using the DESI-HRMS method in order to detect those samples suspected of being crosscontaminated by veterinary drugs.

Feed samples were screened and the acquired mass spectral raw data were interrogated by a custom-made database that included more than 60 veterinary drugs (anthelmintics, antibiotics, coccidiostats, hormones, etc.) commonly used to produce medicated feedstuffs. For each substance, the compound name, the CAS number, the elemental composition and the chemical structure were included. The ionization mode and the expected ions (protonated and deprotonated molecules, adduct ions, in-source fragments, etc.) that can be generated in the DESI source were also added to the custom-made database. 
Feed samples (three replicates) were submitted to the simple sample treatment detailed in the experimental section and analysed by the DESI-HRMS multi-reside method. The sample raw data files were processed using the Exact Finder software and interrogated by the custom-made database to automatically identify the veterinary drugs in the feedstuffs. The criteria applied to confirm the presence of the suspected compounds were the following: a mass accuracy of less than $5 \mathrm{ppm}$ on the exact mass, a minimum signal-to-noise ratio of 3:1 and an isotope cluster fit higher than $80 \%$ (both mass relative deviation and relative intensity differences, for each isotope peak within the cluster ion, were taken into account). Feed samples were also analysed by a wellestablished UHPLC-MS/MS method for the quantification of the identified compounds [10].

Table 1 lists the positive samples and the veterinary drugs identified along with the DESI-HRMS identification criteria and the quantitative results obtained by target UHPLC-MS/MS method. The veterinary drugs at dose levels between $37-107 \mu \mathrm{g} \mathrm{g}^{-1}$ in the medicated feed were easily detected by the DESI-HRMS screening method and only in one of these samples (MF5) an unexpected cross-contamination of monensin $(3.5 \mu \mathrm{g}$ $\mathrm{g}^{-1}$ ) was detected. Fig. 3 shows the DESI-HRMS spectrum of a naransin medicated feed where both narasin and monensin were identified. Additionally, results obtained for non-medicated feed indicated that cross-contamination occurs quite frequently and values above the legislated levels were detected in $28 \%$ of the samples analysed by DESI-HRMS. Coccidiostats (monensin, narasin, decoquinate, nicarbazin, salinomycin and lasalocid), benzimidazoles (oxibendazole), amphenicols (florfenicol), tetracyclines (doxycycline and tetracycline), lincosamides (lincomicyn) and pleuromutilins (tiamulin) were identified in the non-medicated feed samples at concentration levels ranging from 29 to $1.3 \mu \mathrm{g} \mathrm{g}^{-1}$. For most of these samples, the cross-contamination was at concentration levels close to the maximum residue levels, except for sample BF2, where salinomycin was detected at $20 \mu \mathrm{g} \mathrm{g}^{-1}$, a third of the minimum dose recommended for a medicated feed $\left(60 \mu \mathrm{g} \mathrm{g}^{-1}\right)$ [42]. Furthermore, in most of the non-medicated feeds several veterinary drugs were detected in the same sample. For instance, sample BF11 was cross-contaminated with tiamulin $\left(1.7 \mu \mathrm{g} \mathrm{g}^{-1}\right)$ and doxycycline $\left(7.2 \mu \mathrm{g} \mathrm{g}^{-1}\right)$ and in sample BF13 monensin and narasin (at $\left\langle\mu \mathrm{g} \mathrm{g}^{-1}\right.$ level) were positively identified. The UHPLC-MS/MS analysis of the whole set of samples confirmed the DESI-HRMS results and also allowed the identification of additional veterinary drugs at sub- $\mu \mathrm{g} \mathrm{g}^{-1}$ level. However, these low concentration levels are much lower than the maximum residue levels and they are considered unavoidable carry-over. 

suitable to detect cross-contamination of veterinary drugs in feed samples in quality control laboratories since it is simple, with minimum sample manipulation, less time consuming and able to detect cross-contamination at the maximum residue levels legislated.

409

\section{Conclusions}

DESI-HRMS has been shown to be an effective approach for the screening of veterinary drugs in cross-contaminated feedstuffs. A minimal sample manipulation based on a simple extraction procedure (acetonitrile:water $80: 20 \mathrm{v} / \mathrm{v}$ acidified with $1 \%$ formic acid) is proposed to analyse dusty homogenised feed samples. Among the DESI working parameters optimized using nine representative veterinary drugs, the most critical ones for the feed extract analysis were the substrate and the DESI solvent. PTFE substrate and acetonitrile:water $(80: 20 \mathrm{v} / \mathrm{v})$ as DESI solvent provided the highest signal intensity. Although ion suppression due to matrix effects was observed, the sensitivity achieved by DESI-HRMS was enough to identify veterinary drugs as crosscontamination above the legislated levels. Data acquired in high resolution mass spectrometry (70,000 FWHM), processed and interrogated with the custom-made database provided the identification of cross-contamination of non-target veterinary drugs based on accurate mass measurements and isotope cluster fit from HRMS full scan spectra. The results obtained in the feed sample analysis correlated well with those found by UHPLC-MS/MS and demonstrate the potential of the DESI-HRMS as screening method to identify cross-contaminated feedstuffs reducing the number of samples to be quantified by UHPLC-MS/MS in quality control laboratories.

\section{Acknowledgments}

The authors gratefully acknowledge the financial support received from Spanish Ministry of Economy and Competitiveness under the project CTQ2012-30836 and from the Agency for Administration of University and Research Grants (Generalitat de 433 Catalunya, Spain) under the project 2014SGR-539. Raquel Seró is gratefully to the University of Barcelona for an APIF grant. 
436

Conflict of interest:

437 The authors declare that they have no conflict of interest.

438 


\section{References}

1. Council Directive 90/167/EEC of 26 March 1990 laying down the conditions governing the preparation, placing on the market and use of medicated feedingstuffs in the Community. L92:42-48.

2. Stolker AAM, Brinkman UAT (2005) Analytical strategies for residue analysis of veterinary drugs and growth-promoting agents in food-producing animals-a review. J Chromatogr A 1067:15-53.

3. Regulation (EC) No 183/2005 of the European Parliament and of the Council of 12 January 2005 laying down requirements for feed hygiene. L35:1-22.

4. (2010) Directorate General for Health and Consumers Evaluation of the EU Legislative Framework in the Field of Medicated Feed Evaluation of the EU Legislative Framework in the Field of Medicated Feed Final Report. Contract

5. Strauch W (2002) Causes and control of carry-over and cross-contamination: part 1: in production of premixes and compound feed. Kraftfutter 4:151-159.

6. Comission Regulation (EU) No 574/2011 of 16 June 2011 amending Annez I to Directive 2002/32/EC of the European Paliament and of the Council as regards maximum levels for nitrite, melamine, Ambrosia spp. and carry-over of certain coccidiostats and histomon. L159:7-24.

7. Geis-Asteggiante L, Nuñez A, Lehotay SJ, Lightfield AR (2014) Structural characterization of product ions by electrospray ionization and quadrupole time-offlight mass spectrometry to support regulatory analysis of veterinary drug residues in foods. Rapid Commun Mass Spectrom 28:1061-81.

8. Vincent U, Ezerskis Z, Chedin M, von Holst C (2011) Determination of ionophore coccidiostats in feeding stuffs by liquid chromatography-tandem mass spectrometry. Part II. Application to cross-contamination levels and non-targeted feed. J Pharm Biomed Anal 54:526-34.

9. Borràs S, Companyó R, Granados M, Guiteras J, Pérez-Vendrell AM, Brufau J, Medina M, Bosch J (2011) Analysis of antimicrobial agents in animal feed. TrAC Trends Anal Chem 30:1042-1064.

10. Borràs S, Companyó R, Guiteras J, Bosch J, Medina M, Termes S (2013) Multiclass method for antimicrobial analysis in animal feeds by liquid chromatographytandem mass spectrometry. Anal Bioanal Chem 405:8475-86.

11. Van Poucke C, De Keyser K, Baltusnikiene a, McEvoy JD., Van Peteghem C (2003) Liquid chromatographic-tandem mass spectrometric detection of banned antibacterial growth promoters in animal feed. Anal Chim Acta 483:99-109.

12. Mol HGJ, Plaza-bolan P, Zomer P, Rijk TC De, Stolker AAM (2008) Toward a Generic Extraction Method for Simultaneous Determination of Pesticides , Mycotoxins, Plant Toxins, and Veterinary Drugs in Feed and Food Matrixes. 80:9450-9459. 
13. Boscher A, Guignard C, Pellet T, Hoffmann L, Bohn T (2010) Development of a multi-class method for the quantification of veterinary drug residues in feedingstuffs by liquid chromatography-tandem mass spectrometry. J Chromatogr A 1217:6394-404.

14. Robert C, Gillard N, Brasseur P-Y, Pierret G, Ralet N, Dubois M, Delahaut P (2013) Rapid multi-residue and multi-class qualitative screening for veterinary drugs in foods of animal origin by UHPLC-MS/MS. Food Addit Contam Part A Chem Anal Control Expo Risk Assess 30:443-57.

15. Chico J, Rúbies a, Centrich F, Companyó R, Prat MD, Granados M (2008) Highthroughput multiclass method for antibiotic residue analysis by liquid chromatography-tandem mass spectrometry. J Chromatogr A 1213:189-99.

16. Galceran MT, Mart1 A (2009) Fast liquid chromatography / multiple-stage mass spectrometry of coccidiostats. 1255-1263.

17. Kellmann M, Muenster H, Zomer P, Mol H (2009) Full scan MS in comprehensive qualitative and quantitative residue analysis in food and feed matrices: How much resolving power is required? J Am Soc Mass Spectrom 20:1464-1476.

18. Van der Heeft E, Bolck YJC, Beumer B, Nijrolder a WJM, Stolker a a M, Nielen MWF (2009) Full-scan accurate mass selectivity of ultra-performance liquid chromatography combined with time-of-flight and orbitrap mass spectrometry in hormone and veterinary drug residue analysis. J Am Soc Mass Spectrom 20:45163.

19. Peters RJB, Stolker a. a. M, Mol JGJ, Lommen a., Lyris E, Angelis Y, Vonaparti a., Stamou M, Georgakopoulos C, Nielen MWF (2010) Screening in veterinary drug analysis and sports doping control based on full-scan, accurate-mass spectrometry. TrAC Trends Anal Chem 29:1250-1268.

20. Takáts Z, Wiseman JM, Gologan B, Cooks RG (2004) Mass spectrometry sampling under ambient conditions with desorption electrospray ionization. Science 306:471-3.

21. Cody RB, Larame JA (2005) Versatile New Ion Source for the Analysis of Materials in Open Air under Ambient Conditions. 77:2297-2302.

22. Gross JH (2011) Mass Spectrometry. doi: 10.1007/978-3-645-10711-5

23. Li L-P, Feng B-S, Yang J-W, Chang C-L, Bai Y, Liu H-W (2013) Applications of ambient mass spectrometry in high-throughput screening. Analyst 138:3097-103.

24. Nyadong L, Hohenstein EG, Galhena A, Lane AL, Kubanek J, Sherrill CD, Fernández FM (2009) Reactive desorption electrospray ionization mass spectrometry (DESI-MS) of natural products of a marine alga. Anal Bioanal Chem 394:245-54.

25. Laskin J, Laskin A, Roach JP, Slysz GW, Anderson GA, Nizkorodov AS, Bones LD, Nguyen QL (2010) High-Resolution Desorption Electrospray Ionization Mass 

82:2048-2058.

519

520

521

522

523

524

525

526

527

528

529

530

531

532

533

534

535

536

537

538

539

540

541

542

543

544

545

546

547

548

549

550

551

552

553

554

26. Strittmatter N, Düring R-A, Takáts Z (2012) Analysis of wastewater samples by direct combination of thin-film microextraction and desorption electrospray ionization mass spectrometry. Analyst 137:4037-44.

27. Li B, Bjarnholt N, Hansen SH, Janfelt C (2011) Characterization of barley leaf tissue using direct and indirect desorption electrospray ionization imaging mass spectrometry. J Mass Spectrom 46:1241-6.

28. Suni NM, Aalto H, Kauppila TJ, Kotiaho T, Kostiainen R (2012) Analysis of lipids with desorption atmospheric pressure photoionization-mass spectrometry (DAPPIMS) and desorption electrospray ionization-mass spectrometry (DESI-MS). J Mass Spectrom 47:611-9.

29. Zachariasova M, Cajka T, Godula M, Malachova A, Veprikova Z, Hajslova J (2010) Analysis of multiple mycotoxins in beer employing (ultra)-high-resolution mass spectrometry. 3357-3367.

30. Trimpin S, Wang B, Lietz CB, Marshall DD, Richards AL, Inutan ED (2013) New ionization processes and applications for use in mass spectrometry. Crit Rev Biochem Mol Biol 48:409-29.

31. Morelato M, Beavis A, Kirkbride P, Roux C (2013) Forensic applications of desorption electrospray ionisation mass spectrometry (DESI-MS). Forensic Sci Int 226:10-21.

32. Nielen MWF, Hooijerink H, Claassen FC, van Engelen MC, van Beek T a (2009) Desorption electrospray ionisation mass spectrometry: A rapid screening tool for veterinary drug preparations and forensic samples from hormone crime investigations. Anal Chim Acta 637:92-100.

33. Martínez-Villalba A, Vaclavik L, Moyano E, Galceran MT, Hajslova J (2013) Direct analysis in real time high-resolution mass spectrometry for high-throughput analysis of antiparasitic veterinary drugs in feed and food. Rapid Commun Mass Spectrom 27:467-75.

34. Ifa RD, Manicke EN, Allison RL, Cooks RG (2008) Quantitative analysis of small molecules by desorption electrospray ionization mass spectroemtry from polytetrafluoroethylene surfaces. Rapid Commun Mass Spectrom 22:203-510.

35. Takáts Z, Wiseman JM, Cooks RG (2005) Ambient mass spectrometry using desorption electrospray ionization (DESI): Instrumentation, mechanisms and applications in forensics, chemistry, and biology. J Mass Spectrom 40:1261-1275.

36. Green FM, Salter TL, Gilmore IS, Stokes P, O'Connor G (2010) The effect of electrospray solvent composition on desorption electrospray ionisation (DESI) efficiency and spatial resolution. Analyst 135:731. 
37. Costa AB, Cooks RG (2007) Simulation of atmospheric transport and droplet-thin film collisions in desorption electrospray ionization. Chem Commun (Camb) 3915-7.

38. Green FM, Stokes P, Hopley C, Seah MP, Gilmore IS, O’Connor G (2009) Developing Repeatable Measurements for Reliable Desorption Electrospray Ionization. Anal Chem 81:2286-2293.

39. Bodzon-Kulakowska A, Drabik A, Ner J, Kotlinska JH, Suder P (2014) Desorption electrospray ionisation (DESI) for beginners--how to adjust settings for tissue imaging. Rapid Commun Mass Spectrom 28:1-9.

40. Kaklamanos G, Vincent U, von Holst C (2013) Multi-residue method for the detection of veterinary drugs in distillers grains by liquid chromatography-Orbitrap high resolution mass spectrometry. J Chromatogr A 1322:38-48.

41. George K, Vincent U, von Holst C (2013) Analysis of antimicrobial agents in pig feed by liquid chromatography coupled to orbitrap mass spectrometry. $\mathrm{J}$ Chromatogr A 1293:60-74.

42. (2004) Comission Regulation (EC) No 1463/2004 of 17 August 2004 concerning the authorisation for 10 years for the additive "Sacox 120 microGranulate" in feedinstuffs, belonging to the group of coccidiostats and other medicinal substances. Off J Eur Communities 002.001:1-4. 
Fig. 1 DESI-HRMS (+/-) full-scan mass spectrum of a standard mixture with nine representative veterinary drugs. DESI solvent: acetonitrile/water $(80: 20, v / v)$; sample volume: $2 \mu \mathrm{L}$; sample substrate: PTFE

Fig. 2 Effect of the DESI solvent nature (a) and the percentage of acetonitrile in the DESIHRMS signal for some representative veterinary drugs

Fig. 3 DESI-HRMS full scan spectrum obtained from a narasin (NAR) medicated feed (37 $\mu \mathrm{g} \mathrm{g}^{-}$ 584 $\left.{ }^{1}\right)$ cross-contaminated with monensin (MON) $\left(3.5 \mu \mathrm{g} \mathrm{g}^{-1}\right)$ 


\begin{tabular}{|c|c|c|c|c|c|c|c|c|c|}
\hline \multirow[b]{2}{*}{ Sample } & \multirow[b]{2}{*}{$\begin{array}{c}\text { Detected } \\
\text { antibiotics }\end{array}$} & \multirow[b]{2}{*}{$\begin{array}{c}\operatorname{LOD}^{b} \\
\left(\mu g^{-1}\right)\end{array}$} & \multicolumn{6}{|c|}{$\begin{array}{l}\text { DESI-HRMS } \\
\text { screening }\end{array}$} & \multirow{2}{*}{$\begin{array}{c}\begin{array}{c}\text { UHPLC-MS/MS } \\
\text { quantification } \\
(\text { MRL })^{\mathrm{a}}\end{array} \\
\left(\mu \mathrm{g} \mathrm{g}^{-1}\right)\end{array}$} \\
\hline & & & $\begin{array}{c}\text { Exact mass } \\
(m / z)\end{array}$ & $\begin{array}{c}\text { Accurate } \\
\text { mass } \\
(m / z)\end{array}$ & $\begin{array}{c}\text { Ion } \\
\text { assignment }\end{array}$ & $\begin{array}{c}\text { Elemental } \\
\text { composition }\end{array}$ & $\begin{array}{c}\text { Mass } \\
\text { accuracy } \\
(\text { ppm) }\end{array}$ & $\begin{array}{l}\text { Isotopic } \\
\text { cluster } \\
\text { fit }(\%)\end{array}$ & \\
\hline \multicolumn{10}{|c|}{ Medicated feed } \\
\hline MF1 & \multicolumn{2}{|l|}{ Lincomycin } & 407.2210 & 407.2205 & {$[\mathrm{M}+\mathrm{H}]^{+}$} & $\left(\mathrm{C}_{18} \mathrm{H}_{35} \mathrm{~N}_{2} \mathrm{O}_{6} \mathrm{~S}\right)$ & 1.3 & 95 & 107 \\
\hline MF2 & \multicolumn{2}{|l|}{ Monensin } & 693.4184 & 693.4169 & {$[\mathrm{M}+\mathrm{Na}]^{+}$} & $\left(\mathrm{C}_{36} \mathrm{H}_{62} \mathrm{O}_{11} \mathrm{Na}\right)$ & 2.2 & 89 & 100 \\
\hline MF3 & \multicolumn{2}{|l|}{ Monensin } & 693.4184 & 693.4184 & {$[\mathrm{M}+\mathrm{Na}]^{+}$} & $\left(\mathrm{C}_{36} \mathrm{H}_{62} \mathrm{O}_{11} \mathrm{Na}\right)$ & 0.1 & 92 & 87 \\
\hline MF4 & \multicolumn{2}{|l|}{ Narasin } & 787.4967 & 787.4947 & {$[\mathrm{M}+\mathrm{Na}]^{+}$} & $\left(\mathrm{C}_{43} \mathrm{H}_{72} \mathrm{O}_{11} \mathrm{Na}\right)$ & 2.5 & 88 & 44 \\
\hline \multirow{2}{*}{ MF5 } & \multicolumn{2}{|l|}{ Narasin } & 787.4967 & 787.4952 & {$[\mathrm{M}+\mathrm{Na}]^{+}$} & $\left(\mathrm{C}_{43} \mathrm{H}_{72} \mathrm{O}_{11} \mathrm{Na}\right)$ & 1.9 & 84 & 37 \\
\hline & Monensin & $0.5^{\mathrm{c}}$ & 693.4184 & 693.4167 & {$[\mathrm{M}+\mathrm{Na}]^{+}$} & $\left(\mathrm{C}_{36} \mathrm{H}_{62} \mathrm{O}_{11} \mathrm{Na}\right)$ & 2.5 & 80 & $3.5 *(1.25)$ \\
\hline \multicolumn{10}{|c|}{ Non-medicated feed } \\
\hline $\mathrm{BF} 1$ & Florfenicol & $0.7^{\mathrm{d}}$ & 379.9897 & 379.9891 & {$[\mathrm{M}+\mathrm{Na}]^{+}$} & $\left(\mathrm{C}_{12} \mathrm{H}_{14} \mathrm{Cl}_{2} \mathrm{FNO}_{4} \mathrm{SNa}\right)$ & 1.5 & 80 & 7.0 \\
\hline \multirow[t]{3}{*}{$\mathrm{BF} 2$} & Salinomycin & $0.7^{\mathrm{d}}$ & 773.4810 & 773.4794 & {$[\mathrm{M}+\mathrm{Na}]^{+}$} & $\left(\mathrm{C}_{42} \mathrm{H}_{70} \mathrm{O}_{11} \mathrm{Na}\right)$ & 2.1 & 86 & $20 *(0.7)$ \\
\hline & Amoxcillin & $15^{c}$ & 364.0973 & n.d. & {$[\mathrm{M}-\mathrm{H}]^{-}$} & $\left(\mathrm{C}_{16} \mathrm{H}_{19} \mathrm{O}_{5} \mathrm{~N}_{3} \mathrm{~S}\right)$ & --- & --- & 0.13 \\
\hline & Tiamulin & $0.5^{\mathrm{c}}$ & 494.3299 & n.d. & {$[\mathrm{M}+\mathrm{H}]^{+}$} & $\left(\mathrm{C}_{28} \mathrm{H}_{48} \mathrm{NO}_{4} \mathrm{~S}\right)$ & ---- & ---- & 0.11 \\
\hline BF3 & Oxytetracycline & $0.5^{\mathrm{c}}$ & 461.1555 & 461.1546 & {$[\mathrm{M}+\mathrm{H}]^{+}$} & $\left(\mathrm{C}_{22} \mathrm{H}_{25} \mathrm{~N}_{2} \mathrm{O}_{9}\right)$ & 1.9 & 93 & 6.3 \\
\hline $\mathrm{BF} 4$ & Decoquinate & $0.4^{\mathrm{d}}$ & 440.2407 & 440.2412 & {$[\mathrm{M}+\mathrm{Na}]^{+}$} & $\left(\mathrm{C}_{24} \mathrm{H}_{35} \mathrm{NO}_{5} \mathrm{Na}\right)$ & 1.1 & 91 & $5.0 *(0.4)$ \\
\hline BF5 & Decoquinate & $0.4^{\mathrm{d}}$ & 440.2407 & 440.2410 & {$[\mathrm{M}+\mathrm{Na}]^{+}$} & $\left(\mathrm{C}_{24} \mathrm{H}_{35} \mathrm{NO}_{5} \mathrm{Na}\right)$ & 0.5 & 89 & $3.3 *(0.4)$ \\
\hline BF6 & Lasalocid & $0.4^{\mathrm{d}}$ & 613.3711 & 613.3705 & {$[\mathrm{M}+\mathrm{Na}]^{+}$} & $\left(\mathrm{C}_{34} \mathrm{H}_{54} \mathrm{O}_{8} \mathrm{Na}\right)$ & 1.0 & 80 & $0.45(1.25)$ \\
\hline & Decoquinate & & 440.2407 & n.d. & {$[\mathrm{M}+\mathrm{Na}]^{+}$} & $\left(\mathrm{C}_{24} \mathrm{H}_{35} \mathrm{NO}_{5} \mathrm{Na}\right)$ & ---- & ---- & $0.21(0.4)$ \\
\hline BF7 & Narasin & $0.5^{\mathrm{c}}$ & 787.4967 & 787.4957 & {$[\mathrm{M}+\mathrm{Na}]^{+}$} & $\left(\mathrm{C}_{43} \mathrm{H}_{72} \mathrm{O}_{11} \mathrm{Na}\right)$ & 1.2 & 84 & $1.3 *(0.7)$ \\
\hline BF8 & Tiamulin & $0.5^{\mathrm{c}}$ & 494.3299 & 494.3288 & {$[\mathrm{M}+\mathrm{H}]^{+}$} & $\left(\mathrm{C}_{28} \mathrm{H}_{48} \mathrm{NO}_{4} \mathrm{~S}\right)$ & 2.1 & 86 & 1.6 \\
\hline & Amoxicillin & $15^{\mathrm{c}}$ & 364.0973 & n.d. & {$[\mathrm{M}-\mathrm{H}]^{-}$} & $\left(\mathrm{C}_{16} \mathrm{H}_{19} \mathrm{O}_{5} \mathrm{~N}_{3} \mathrm{~S}\right)$ & ---- & ---- & 0.80 \\
\hline BF9 & Narasin & $0.5^{\mathrm{c}}$ & 787.4969 & 787.4955 & {$[\mathrm{M}+\mathrm{Na}]^{+}$} & $\left(\mathrm{C}_{43} \mathrm{H}_{72} \mathrm{O}_{11} \mathrm{Na}\right)$ & 1.5 & 89 & $2.1 *(0.7)$ \\
\hline & Nicarbazin & & 301.0573 & n.d. & {$[\mathrm{M}-\mathrm{H}]^{-}$} & $\left(\mathrm{C}_{19} \mathrm{H}_{18} \mathrm{O}_{6} \mathrm{~N}_{6}\right)$ & ---- & ---- & $0.42(1.25)$ \\
\hline BF10 & Narasin & $0.5^{\mathrm{c}}$ & 787.4969 & 787.4967 & {$[\mathrm{M}+\mathrm{Na}]^{+}$} & $\left(\mathrm{C}_{43} \mathrm{H}_{72} \mathrm{O}_{11} \mathrm{Na}\right)$ & 1.3 & 91 & $29 *(0.7)$ \\
\hline BF11 & Tiamulin & $0.5^{\mathrm{c}}$ & 494.3299 & 494.3297 & {$[\mathrm{M}+\mathrm{H}]^{+}$} & $\left(\mathrm{C}_{28} \mathrm{H}_{48} \mathrm{NO}_{4} \mathrm{~S}\right)$ & 0.4 & 83 & 1.7 \\
\hline & Doxycycline & $1.2^{\mathrm{c}}$ & 463.1711 & 463.1714 & {$[\mathrm{M}+\mathrm{H}]^{+}$} & $\left(\mathrm{C}_{22} \mathrm{H}_{27} \mathrm{~N}_{2} \mathrm{O}_{9}\right)$ & 0.6 & 94 & 7.2 \\
\hline & Amoxcillin & $15^{\mathrm{c}}$ & 364.0973 & n.d. & {$[\mathrm{M}-\mathrm{H}]^{-}$} & $\left(\mathrm{C}_{16} \mathrm{H}_{19} \mathrm{O}_{5} \mathrm{~N}_{3} \mathrm{~S}\right)$ & ---- & ---- & 2.0 \\
\hline BF12 & Decoquinate & $0.4^{\mathrm{d}}$ & 440.2407 & 440.2413 & {$[\mathrm{M}+\mathrm{Na}]^{+}$} & $\left(\mathrm{C}_{24} \mathrm{H}_{35} \mathrm{NO}_{5} \mathrm{Na}\right)$ & 1.2 & 88 & $5.0 *(0.4)$ \\
\hline BF13 & Narasin & $0.5^{\mathrm{c}}$ & 787.4967 & 787.4964 & {$[\mathrm{M}+\mathrm{Na}]^{+}$} & $\left(\mathrm{C}_{43} \mathrm{H}_{72} \mathrm{O}_{11} \mathrm{Na}\right)$ & 0.3 & 83 & $1.7 *(0.7)$ \\
\hline & Monensin & $0.5^{\mathrm{c}}$ & 693.4184 & 693.4187 & {$[\mathrm{M}+\mathrm{Na}]^{+}$} & $\left(\mathrm{C}_{36} \mathrm{H}_{62} \mathrm{O}_{11} \mathrm{Na}\right)$ & 0.3 & 84 & $1.6^{*}(1.25)$ \\
\hline & Robenidine & & 334.0621 & n.d. & {$[\mathrm{M}+\mathrm{H}]^{+}$} & $\left(\mathrm{C}_{15} \mathrm{H}_{13} \mathrm{Cl}_{2} \mathrm{~N}_{5}\right)$ & ---- & ---- & $0.32(0.7)$ \\
\hline & Diclazuril & $1^{\mathrm{c}}$ & 404.9718 & n.d. & {$[\mathrm{M}-\mathrm{H}]^{-}$} & $\left(\mathrm{C}_{17} \mathrm{H}_{9} \mathrm{Cl}_{3} \mathrm{O}_{2} \mathrm{~N}_{4}\right)$ & ---- & ---- & $0.01 *(0.01)$ \\
\hline BF14 & Amoxicillin & $15^{c}$ & 364.0973 & n.d. & {$[\mathrm{M}-\mathrm{H}]^{-}$} & $\left(\mathrm{C}_{16} \mathrm{H}_{19} \mathrm{O}_{5} \mathrm{~N}_{3} \mathrm{~S}\right)$ & ---- & ---- & 0.17 \\
\hline & Tiamulin & $0.5^{\mathrm{c}}$ & 494.3299 & n.d. & {$[\mathrm{M}+\mathrm{H}]^{+}$} & $\left(\mathrm{C}_{28} \mathrm{H}_{48} \mathrm{NO}_{4} \mathrm{~S}\right)$ & ---- & ---- & 0.50 \\
\hline BF15 & Oxibendazole & $0.5^{\mathrm{c}}$ & 250.1186 & 250.1188 & {$[\mathrm{M}+\mathrm{H}]^{+}$} & $\left(\mathrm{C}_{12} \mathrm{H}_{16} \mathrm{~N}_{3} \mathrm{O}_{3}\right)$ & ---- & ---- & 0.13 \\
\hline BF16 & Amoxcillin & $15^{\mathrm{c}}$ & 364.0973 & n.d. & {$[\mathrm{M}-\mathrm{H}]^{-}$} & $\left(\mathrm{C}_{16} \mathrm{H}_{19} \mathrm{O}_{5} \mathrm{~N}_{3} \mathrm{~S}\right)$ & ---- & ---- & 0.17 \\
\hline & Lincomycin & $0.5^{\mathrm{c}}$ & 407.2210 & n.d. & {$[\mathrm{M}+\mathrm{H}]^{+}$} & $\left(\mathrm{C}_{18} \mathrm{H}_{35} \mathrm{~N}_{2} \mathrm{O}_{6} \mathrm{~S}\right)$ & --- & ---- & 0.25 \\
\hline & Oxibendazole & $0.5^{\mathrm{c}}$ & 250.1186 & n.d. & {$[\mathrm{M}+\mathrm{H}]^{+}$} & $\left(\mathrm{C}_{12} \mathrm{H}_{16} \mathrm{~N}_{3} \mathrm{O}_{3}\right)$ & ---- & ---- & 0.20 \\
\hline & Tiamulin & $0.5^{\mathrm{c}}$ & 494.3299 & n.d. & {$[\mathrm{M}+\mathrm{H}]^{+}$} & $\left(\mathrm{C}_{28} \mathrm{H}_{48} \mathrm{NO}_{4} \mathrm{~S}\right)$ & ---- & ---- & 0.18 \\
\hline $\mathrm{BF} 17$ & Amoxcillin & $15^{c}$ & 364.0973 & n.d. & {$[\mathrm{M}-\mathrm{H}]^{-}$} & $\left(\mathrm{C}_{16} \mathrm{H}_{19} \mathrm{O}_{5} \mathrm{~N}_{3} \mathrm{~S}\right)$ & ---- & --- & 0.15 \\
\hline & Lincomycin & $0.5^{\mathrm{c}}$ & 407.2210 & n.d. & {$[\mathrm{M}+\mathrm{H}]^{+}$} & $\left(\mathrm{C}_{18} \mathrm{H}_{35} \mathrm{~N}_{2} \mathrm{O}_{6} \mathrm{~S}\right)$ & ---- & ---- & 0.39 \\
\hline BF18 & Nicarbazin & & 301.0573 & n.d. & {$[\mathrm{M}-\mathrm{H}]^{-}$} & $\left(\mathrm{C}_{19} \mathrm{H}_{18} \mathrm{O}_{6} \mathrm{~N}_{6}\right)$ & --- & ---- & $0.16(1.25)$ \\
\hline & ${ }^{\mathbf{a}} \mathrm{Maxi}$ & resic & levels legis & ed in Dire & ve $574 / 201$ & & & & \\
\hline & ${ }^{\mathbf{b}}$ Limits & Detec & LOD) ca & ted by & I-HRMS & & & & \\
\hline & ${ }^{\mathbf{c}}$ LODs & imated $\mathrm{l}$ & spiking blar & feed extra & ts with stand & & & & \\
\hline & ${ }^{\mathrm{d}}$ LODs & lculated & aking into ace & ound the co & centration les & quantified by HPL & MS/MS & & \\
\hline & $*(\mathrm{MRL})$ & & & & & & & & \\
\hline
\end{tabular}




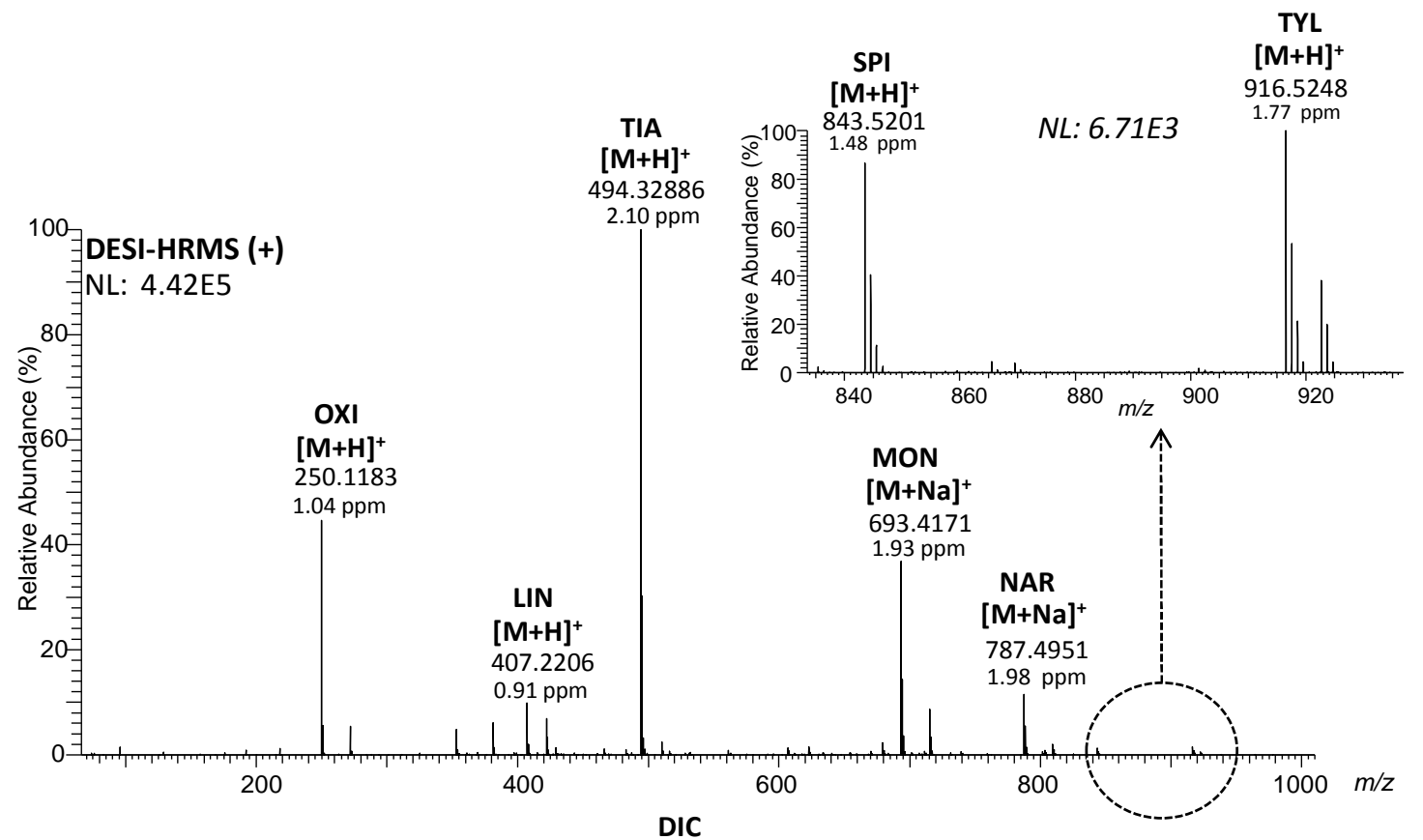

[M-H]

404.9723

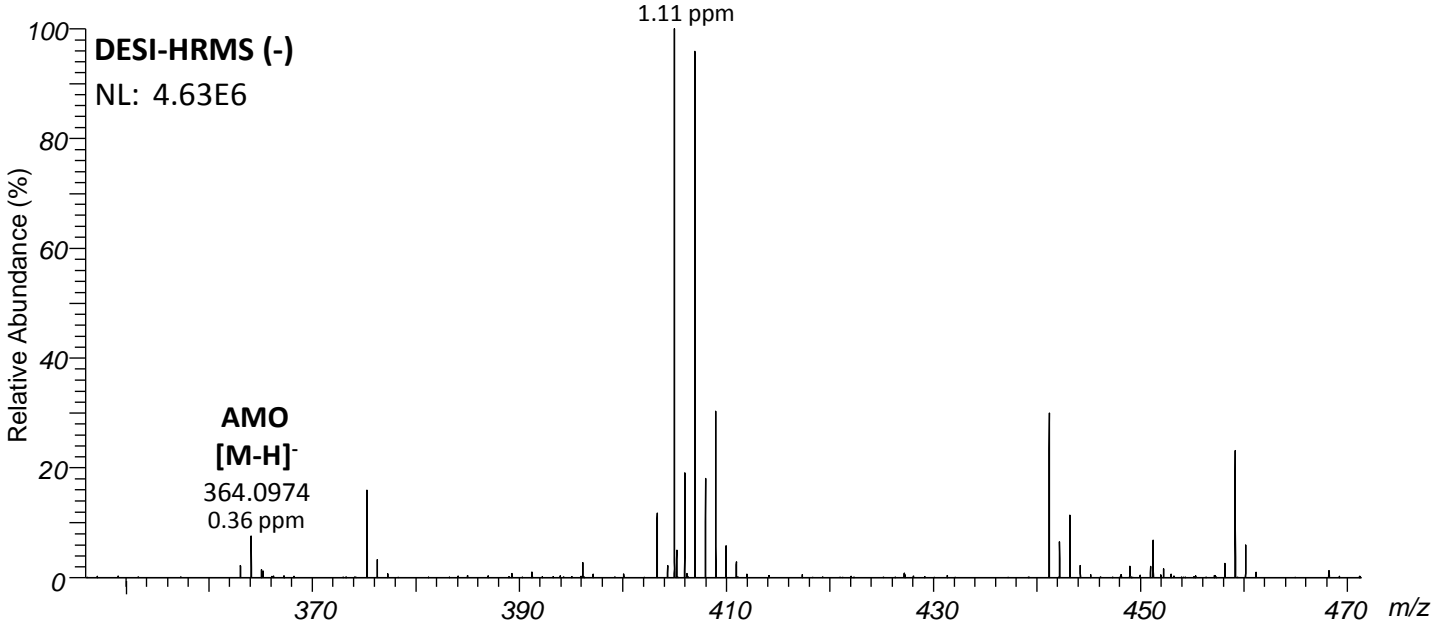



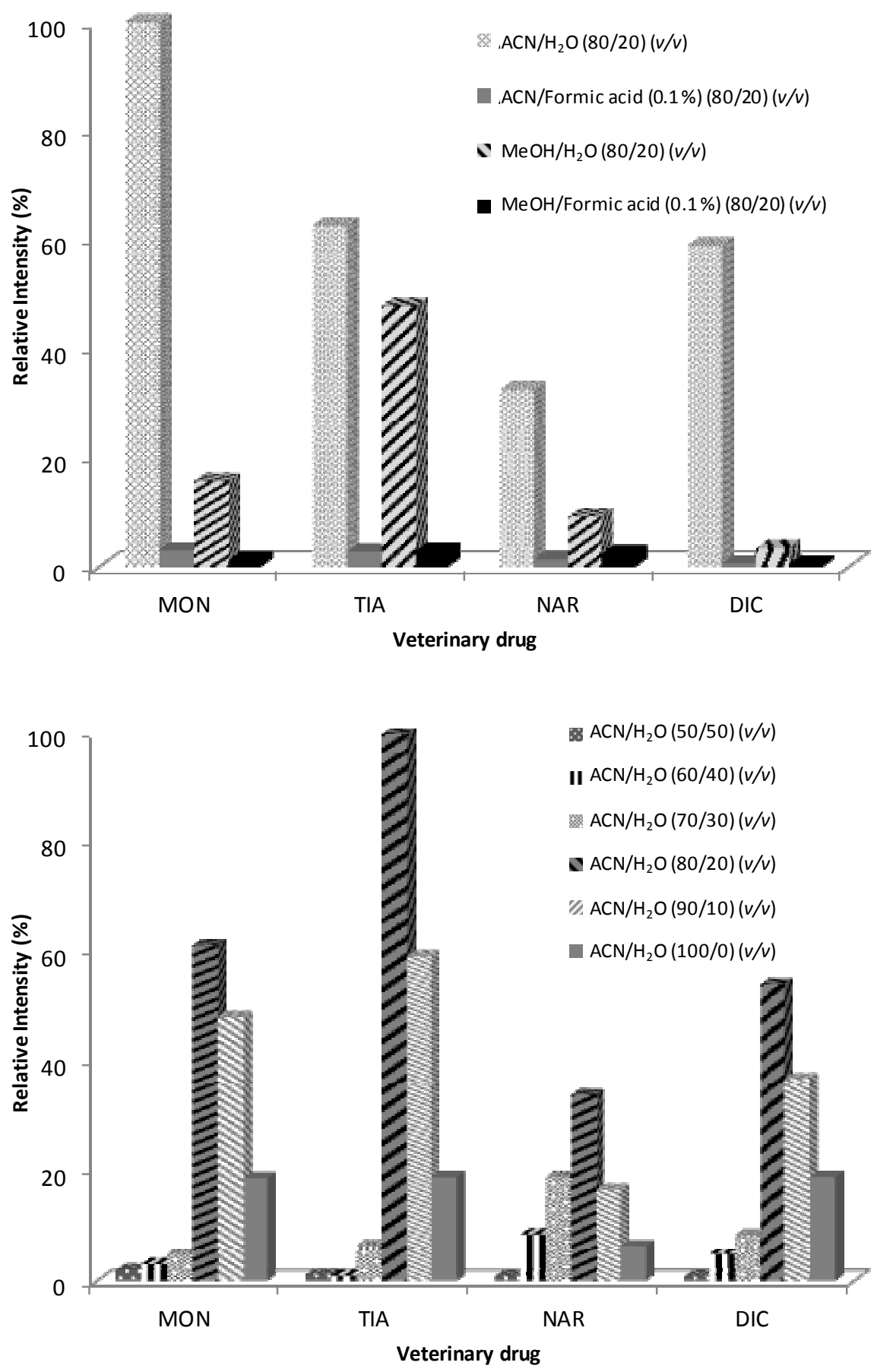
DESI-HRMS (+)

NAR

[M+Na] $^{+}$

787.4952

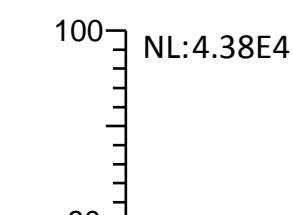

$1.9 \mathrm{ppm}$

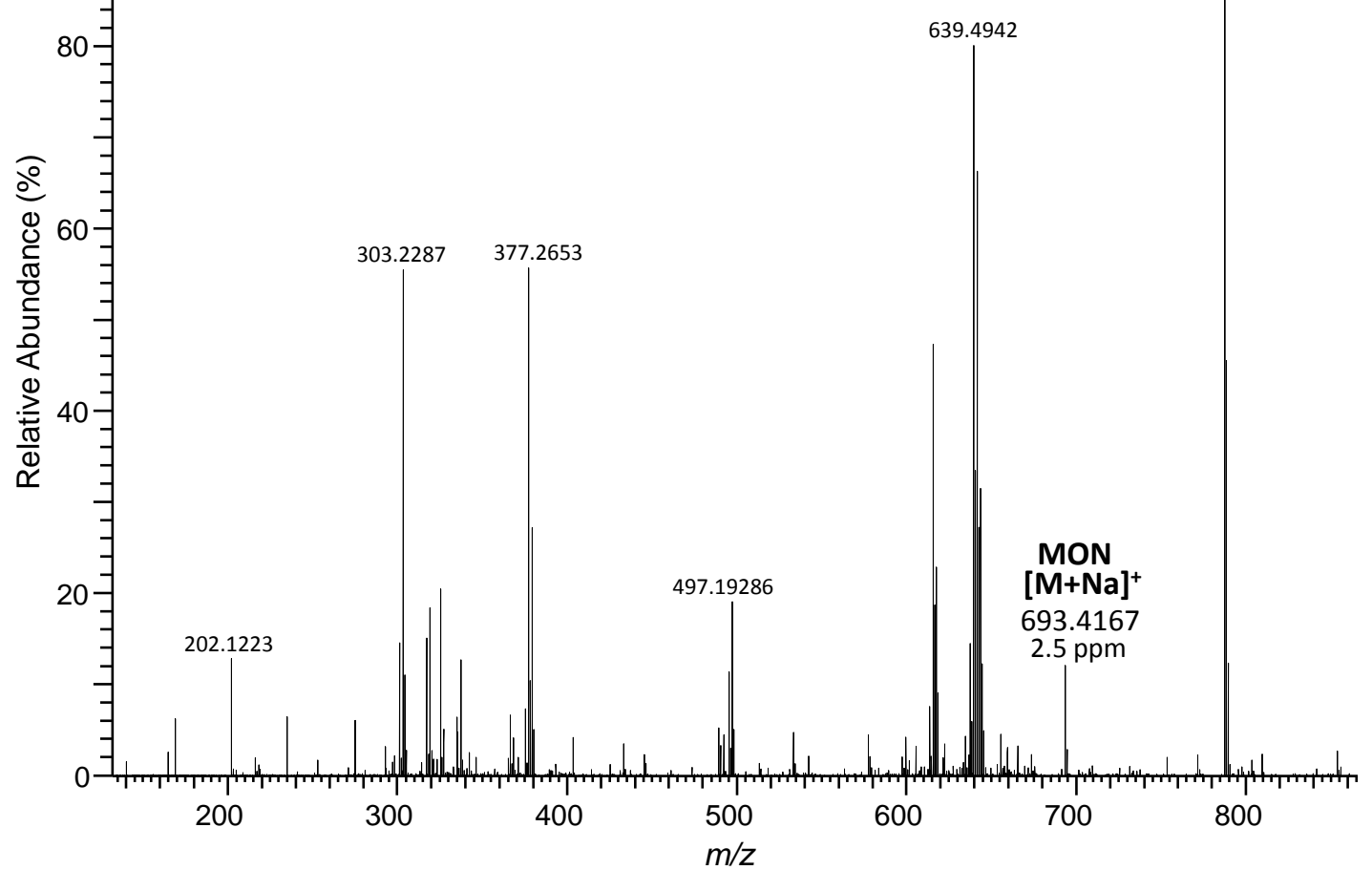

635 